\title{
PENDIDIKAN AGAMA ANAK SUKU KALANG
}

\author{
Misbah Zulfa E. \\ Unversitas Gadjah Mada Yogyakarta \\ e-mail: elly_sholihan@yahoo.com
}

\begin{abstract}
This study with descriptive qualitative approach produces a fact that the context of education, the children of the kalang community in general are also followed formal education, like other school children. They also received religious instruction as a compulsory subject. This of course has consequences for the possibility of cultural transformation through the instrument of education. Especially with religious education, the children of the Kalang community possible simultaneously and slowly will leave their teachings. Moreover, the nature of religious education itself is more of an orthodox religious values.

$* * *$

Kajian dengan pendekatan deskritif ini menyajikan fakta bahwa konteks pendidikan, anak-anak suku Kalang secara umum mengikuti pendidikan formal, sebagaimana anak-anak lain pada umumnya. Mereka juga menerima pelajaran agama sebagai pelajaran wajib. Hal ini tentu saja berpengaruh terhadap kemungkinan terjadinya transformasi budaya melalui instrumen pendidikan. Khususnya terkait dengan pendidikan agama, anak-anak suku Kalang dimungkinkan secara simultan dan perlahan akan meninggalkan ajarannya. Apalagi model pendidikan agama yang mereka terima adalah pendidikan yang lebih banyak memuat nilai-nilai ortodoks.
\end{abstract}

Keywords: pendidikan, agama, budaya, suku Kalang 


\section{A. Pendahuluan}

Pendidikan dipahami sebagai "usaha sadar, terarah, dan disertai dengan pemahaman yang baik, untuk menciptakan perubahan-perubahan yang diharapkan pada perilaku individu, dan selanjutnya pada perilaku komunitas di mana individu itu hidup. Pada bagian lain, pendidikan merupakan suatu proses yang bertujuan untuk membudayakan manusia. ${ }^{1}$ Orientasi pembudayaan ini memiliki implikasi bahwa terjadi proses penanaman nilai yang kemudian diekspresikan dalam berbagai tingkah laku, baik yang bersifat verbal maupun non verbal. Orientasi pembudayaan itu pula yang mengarahkan pendidikan ke arah norma yang secara mainstream berlaku. Dalam konteks semacam ini pendidikan tampaknya sangat superior karena mendominasi sistem dan isi pendidikan.

Dalam pelaksanaannya, untuk tujuan tercapainya tujuan pendidikan, maka pendidikan diatur oleh ketetapan negara. Salah satu ketetapan negara terkait dengan pendidikan adalah tentang usia anak sekolah. Dikenallah kemudian WAJAR yang merupakan perpanjangan dari wajib belajar. Istilah ini merujuk pada ketentuan bahwa semua anak Indonesia yang berada dalam usia sekolah, wajib untuk mengikuti program pendidikan formal. Jenjang yang disyaratkan untuk pendidikan warga negara Indonesia adalah pendidikan dasar. Pendidikan dasar dalam konteks ini ditetapkan dengan jenjang pendidikan di sekolah dasar ( 6 tahun) dan sekolah menengah pertama (3 tahun).

Realitas yang berlaku di Indonesia dalam konteks kini adalah bahwa muatan pendidikan disusun dalam sebuah acuan baku yang disebut dengan kurikulum nasional. Di dalam kurikulum nasional tersebut ditetapkan sejumlah mata pelajaran wajib yang harus diberikan dalam setiap jenjang pendidikan. Salah satu mata pelajaran yang wajib diberikan adalah pendidikan agama. Pendidikan agama dalam kaitan ini adalah pendidikan agama untuk penganut agama-agama formal di bumi Indonesia ini.

Menurut Alex R. Rodger, pendidikan agama merupakan bagian integral dari pendidikan pada umumnya. Jika pendidikan umum lebih bersifat memperluas cakrawala pengetahuan ataupun horison pengetahuan, sedangkan

1 H.A.R. Tilaar, Kekuasaan dan Pendidikan, Suatu Tinjauan dari Perspektif Studi Kultural, (Jakarta: Indonesia Tera, 2003). 
pendidikan agama ditujukan untuk membantu perkembangan pengertian yang dibutuhkan bagi orang-orang tentang ajaran agama, sekaligus untuk memperkuat ortodoksi keimanan bagi mereka. ${ }^{2}$ Muatan "agama" dalam pendidikan agama menjadi "inti" dari pembentukan kesadaran tentang suatu agama dan pada gilirannya akan membentuk pribadi-pribadi ataupun komunitas yang mempunyai kesadaran religious.

Sebuah realitas yang ada di depan mata kita adalah bahwa masyarakat Indonesia adalah masyarakat yang multi-kultur. Masyarakat multi kultur di sini memiliki makna bahwa bangsa Indonesia terdiri dari banyak suku bangsa dengan berbagai karakteristiknya. Karakteristik dimaksud di sini antara lain adalah karakteristik bahasa, sistem sosial, sistem teknologi, sistem mata pencaharian, dan sistem nilai. ${ }^{3}$ Terkait dengan sistem nilai ini, dalam masyarakat yang multikultur, sistem nilai yang dimaksudkan tidak semata berkaitan dengan agama formal, namun juga berkaitan dengan sistem nilai lokal yang spesifik bagi suatu kelompok suku bangsa atau komunitas di Indonesia, ${ }^{4}$ sehingga pendidikan dan budaya tidak dapat dipisahkan. Salah satu komunitas budaya yang ada di Indonesia, yang secara spesifik di Jawa Tengah, adalah Komunitas Kalang.

Orang Jawa memandang Orang Kalang sebagai masyarakat primitif. Posisi orang Kalang disejajarkan dengan orang Dayak (Kalimantan), Badui (Jawa Barat), orang Asli (penduduk asli Semenanjung Malaysia) yang dianggap terbelakang, bodoh dan kurang beradab dibandingkan dengan kelompok-kelompok etnis lainnya di Indonesia. Orang Kalang distereotipkan sebagai "penduduk asli". Menurut pandangan Eriksen, "penduduk asli" (indigineus people) merupakan istilah antropologi yang biasa digunakan untuk menggambarkan kelompok non-dominan di dalam sebuah wilayah tertentu yang dianggap relatif aboriginal. ${ }^{5}$ Meskipun sebenarnya penyebutan "penduduk asli" secara konseptual kurang tepat dalam konteks penyebutan orang Kalang di Indonesia, namun penyebutan tersebut cukup memberikan

${ }^{2}$ Alex R. Rodger, Education and Faith in an Open Society, (Edinburgh: Handsel Press, 1982), h. 61.

3 Baca: Koentjaraningrat, Pengantar Ilmu Antropologi, (Jakarta, Rineka Cipta, 2002).

4 Barth, Fredrik, Ethnic Groups and Boundaries: The Social Organization of Culture Difference, (Bergen: Waveland Press, 1998).

5 Thomas Hylland Eriksen, Identity and Nationalism, (London: Pluto Pres 2002), p. 14. 
kesan bahwa orang Kalang merupakan komunitas yang terbelakang dibanding suku Jawa.

Keberadaan Wong Kalang sendiri diyakini sudah ada sejak awal Kerajaan Mataram. Tepatnya ketika Mataram diperintah Sultan Agung. Namun demikian, ada pendapat lain yang menduga keberadaan Wong Kalang sudah ada sebelum pengaruh Hindu masuk ke Jawa. Pendapat itu berdasar pada temuan istilah Kalang dalam prasasti Kuburan Candi di Tegalsari, Tegalharjo, Kabupaten Magelang, yang berangka tahun 753 Saka atau 831 Masehi.

Dewasa ini keluarga atau keturunan Wong Kalang banyak terdapat di kawasan pinggiran pegunungan selatan Jawa Tengah, seperti di Kebumen, Purworejo, Cilacap, dan Surakarta. Di Kabupaten Kebumen, keluarga Kalang tersebar di Petanahan, Puring, Gombong, Karanganyar dan Ambal. Di Cilacap, banyak terdapat di sekitar Adipala. Sedangkan di Yogyakarta, pada zaman kolonial Belanda dulu mereka banyak tinggal di Kotagede (Ada juga pendapat yang mengatakan mereka sudah tinggal di tempat ini sejak zaman Kerajaan Mataram). Kini keluarga Kalang di Yogyakarta menyebar di sejumlah wilayah. Sisa-sisa kejayaan Wong Kalang di Kotagede (Tegalgendu dan Mondoraka) sampai sekarang masih dapat ditemukan. Bangunan-bangunan lama (kuno) di seputar Tegalgendu dan Mondoraka yang besar, bertembok tebal, dengan hiasan kaca-kaca Art Deco, dan bentuk arsitekturnya berbeda dengan lazimnya rumah-rumah biasa orang Jawa, merupakan sisa-sisa peninggalan keluarga Kalang. Dan, salah satu di antaranya adalah rumah besar, mewah dan antik, di Tegal Gendu, yang terkenal dengan sebutan "Omah Dhuwur" oleh para ahli dipandang sebagai ciri dari tempat tinggal suku Kalang ini.

Di kawasan pesisir utara Jawa Tengah, keluarga Kalang banyak tinggal di Tegal, Pekalongan, Kendal, Kaliwungu, Semarang, dan Pati. Di Jawa Timur, keluarga Kalang banyak terdapat di Bojonegoro, Surabaya, Bangil, Pasuruan, Tulungagung dan Malang.

Pada masa Paku Buwono II, jumlah Orang Kalang mencapai 6.000 keluarga dan 1.000 cacah. Ketika wilayah pesisir jatuh ke tangan VOC, orangOrang Kalang juga dimanfaatkan untuk menebang kayu. Surat Jac Couper dari Jepara kepada Hoge Regering tertanggal 4 November 1675 menyebut keberadaan orang-orang Kalang dalam jumlah besar sebagai penebang kayu di hutan jati daerah Rembang dan Pati. Tahun 1743, jumlah Orang Kalang di wilayah kekuasaan VOC mencapai 2.780 keluarga. Secara geografis, mereka 
tersebar di berbagai daerah pesisir Jawa. Mereka tersebar di Surabaya (250 keluarga), Pasuruhan (50), Pati (250), Demak (1000), Pekalongan (800), Tegal (180) dan Kendal (250). Di luar itu, orang-orang Kalang juga bermukim di Cilacap, Adipala, Gombong, Ambar Karanganyar, Petanahan, Solo, Yogyakarta, Tulungagung dan Malang. ${ }^{6}$

Orang-orang Kalang mempunyai bahasa, adat istiadat dan agama sebagaimana umumnya orang Jawa. Sungguhpun demikian, mereka mempunyai pemahaman dan interpretasi yang berbeda, khususnya adat istiadat dan agama. Salah satu hal yang menarik dari sistem kepercayaan komunitas Kalang adalah yang terkait dengan genealogi komunitas tersebut. Orang Kalang menyakini bahwa mereka keturunan anjing. Mitos genealogis ini direproduksi secara transmisional antar generasi. Kepercayaan ini melahirkan adat istiadat yang lazim disebut ritual "gegalungan", yakni pemujaan terhadap "patung anjing", sebagai bentuk penghormatan terhadap arwah nenek moyang mereka.7 Dalam ritual ini, mereka berharap kedatangan "ruh" anjing yang bersifat "gaib", sebagai ruh nenek moyang mereka. Kedatangan ruh "anjing" dalam ritual diyakini mereka dapat terlihat pada bekas telapak kaki yang ditinggalkan pada area pemujaan. ${ }^{8}$

Dalam konteks pendidikan, anak-anak orang kalang pada umumnya juga mengikuti pendidikan formal, seperti anak sekolah lainnya. Mereka juga mendapatkan pelajaran agama sebagai mata pelajaran wajib. Hal ini tentu membawa konsekuensi bagi kemungkinan terjadinya transformasi budaya melalui instrumen pendidikan. Terlebih dengan pendidikan agama, anakanak orang Kalang dimungkinkan secara simultan dan perlahan akan meninggalkan ajaran-ajaran Kalang. Apalagi sifat pendidikan agama itu sendiri yang lebih bersifat sebagai ortodoksi nilai-nilai agama.

Pada bagian lain, orang Kalang umumnya mempunyai harapan besar terhadap anak-anak mereka sebagai generasi yang dapat meneruskan kelangsungan budaya Kalang. Selama ini proses "pewarisan" nilai-nilai Kalang, terbatas hanya pada pendidikan keluarga. Pendidikan keluarga menjadi instrumen utama untuk mengintrodusir nilai-nilai budaya identitas sekaligus

${ }^{6}$ Ahmad Sholeh, ibid., h. 8. Lihat Suara Merdeka, 31 Januari 2008.

${ }^{7}$ Sulardjo Pontjosutirto, "Antropologi Orang Kalang," laporan penelitian FH UGM, 1971. h. 70.

${ }^{8}$ Lihat Suara Merdeka, 31 Januari 2008. 
sebagai filter atas pengaruh-pengaruh luar. Pertanyaannya adalah seberapa kuat pertahanan "keluarga" dalam menghadapi serangan-serangan pengaruh luar? Harapan para orang tua Kalang tentu mendapat serangkaian tantangan yang tidak kecil. Di samping arus modernisasi, pendidikan formal turut menjadi variabel penting bagi kemungkinan terjadinya enkulturasi budaya dalam diri masyarakat kalang, utamanya melalui anak-anak orang Kalang.

Dari paparan di atas mendorong peneliti untuk melakukan kajian mendalam, khususnya tentang "Pendidikan Agama Anak Suku Kalang". Penelitian ini dilakukan terutama untuk memotret perihal pendidikan "agama" anak orang kalang dan proses enkulturasi "budaya" kaum minoritas marginal dalam supraetnis Jawa.

\section{B. Pendidikan dan Kebudayaan}

Eksistensi suatu kebudayaan diperoleh melalui proses pendidikan. Setiap komunitas kebudayaan yang memiliki lembaga-lembaga pendidikan sebagai salah satu unsur dalam komunitas kebudayaan dalam upaya untuk mempertahankan komunitas tersebut. Akan tetapi proses transmisi kebudayaan tidak terjadi secara otomatis, namun selalu mengalami transformasi. Transformasi kebudayaan bukan semata bersifat reproduksi, namun juga berupa perubahan. ${ }^{9}$

Pengaruh budaya dapat dipilah ke dalam dua aspek hubungan keluarga: perkembangan individu serta tujuan kolektif. Aspek perkembangan individu melibatkan suatu budaya tertentu dan perannya dalam sosialisasi keluarga, namun kondisi ini rumit untuk dipahami karena budaya secara tetap ditransformasikan ketika individu menegosiasikan makna interaksi sosial. Dalam konteks ini individu sangat dipengaruhi oleh latar belakang pendidikannya.

Sekolah menurut Basil Bernstein memiliki ritual yang berkait dengan tatanan consensual ritual dan differentiating ritual. Consensual ritual adalah suatu ritual yang memberikan fungsi menyatukan semua anggota sekolah sebagai suatu komunitas moral dan kolektivitas yang khas. Ritual ini memungkinkan keberlangsungan sekolah dari masa ke masa. Ritual ini pula yang menciptakan kembali apa yang ada pada masa lalu ke masa sekarang

\footnotetext{
${ }_{9}$ Pierre Bourdieu and Jean Claude Passeron, Reproduction in Education, Society and Culture, revised edition, (New York: SAGE, 1990).
} 
dan menetapkannya sebagai proyek untuk masa yang akan datang. Ritual ini juga mengkaitkan nilai yang dipegang sekolah dengan nilai yang ada di dalam masyarakat sebagai kelompok dominan di luar sekolah. Ritual yang kedua adalah differentiating ritual. Ritual ini memiliki makna bahwa sekolah melakukan pembedaan satu sama lain, yang biasanya terkait dengan usia, jenis kelamin, dan hubungan usia dengsn fungsi sosial. Ritual ini memunculkan perilaku yang mendekatkan atau menjauhkan anggota sekolah dengan kelompok-kelompok tertentu; misalnya berilaku hormat terhadap berbagai posisi autporitas serta menciptakan tatanan tertentu. ${ }^{10}$

Kedua jenis ritual ini merupakan mekanisme utama untuk menginternalisir dan menghidupkan kembali tatanan sosial. Ritual ini berfungsi untuk mempertahankan kontinuitas, tatanan, batasan, dan kontrol kesetiaan dan ambivalensi dari para penyokong kebudayaan.

Menurut Piere Bourdieu dan Jean Claude, sistem pendidikan mengesahkan transmisi kekuasaan dari generasi satu ke generasi lainnya. ${ }^{11}$ Salah satu fungsi pendidikan adalah transmisi budaya. Melalui pendidikan suatu budaya dapat ditransmisikan kepada generasi mudanya. Pada sisi lain, sebagai suatu sistem, kebudayaan tidak diperoleh manusia dengan begitu saja secara ascribed, tetapi juga melalui proses belajar yang berlangsung tanpa henti. Proses belajar dalam konteks kebudayaan bukan hanya dalam bentuk internalisasi dari sistem "pengetahuan" yang diperoleh manusia melalui pewarisan atau transmisi dalam keluarga, lewat sistem pendidikan formal di sekolah atau lembaga pendidikan formal lainnya, melainkan juga diperoleh melalui proses belajar dari berinteraksi dengan lingkungan alam dan sosialnya. Melalui pewarisan kebudayaan dan internalisasi pada setiap individu, pendidikan hadir dalam bentuk sosialisasi kebudayaan, berinteraksi dengan nilai-nilai masyarakat setempat dan memelihara hubungan timbal balik yang menentukan proses-proses perubahan tatanan sosio-kultur masyarakat dalam rangka mengembangkan kemajuan peradabannya.

Antara pendidikan dan kebudayaan terdapat hubungan yang sangat erat dalam arti keduanya berkenaan dengan suatu hal yang sama yakni nilai-nilai. Dalam konteks kebudayaan justru "pendidikan" memainkan peranan sebagai

${ }^{10}$ Class, Codes, and Control. Vol. 1, "Theoretical Studies toward a Sociology of Language by Basil Bernstein," (London: Routledge \& Kegan Paul, 1971).

11 Pierre Bourdieu and Jean Claude Passeron, Reproduction in Education ..... 
agen pengajaran nilai-nilai budaya. Dari paparan terakhir dapat ditangkap bahwa pada dasarnya pendidikan yang berlangsung adalah suatu proses pembentukan kualitas manusia sesuai dengan kodrat budaya yang dimiliki.

Afinitas mengenai pendidikan dan kebudayaan dapat kita cermati dalam ciri khas manusia sebagai makhluk simbolik. Hanya manusialah yang mengenal dan memanfaatkan simbol-simbol di dalam kelanjutan kehidupannya. Simbol-simbol itu dapat kita lihat di dalam kebudayaan manusia. Mengingat kebudayaan dilestarikan dan dikembangkan melalui simbol-simbol maka semua tingkah laku manusia terdiri dari, dan tergantung pada simbol-simbol tersebut. Sebaliknya kebudayaan bisa lestari apabila memiliki daya kerja yang kuat dalam memberikan arahan para pendukungnya. Oleh karena itu kebudayaan diturunkan kepada generasi penerusnya lewat proses belajar tentang tata cara bertingkah laku. Sehingga secara wujudnya, substansi kebudayaan itu telah mendarah daging dalam kepribadian anggota-anggotanya.

Fungsi pendidikan dalam konteks kebudayaan dapat dilihat dalam perkembangan kepribadian manusia. Tanpa kepribadian manusia tidak ada kebudayaan, meskipun kebudayaan bukanlah sekadar jumlah kepribadiankepribadian. Para pakar antropologi, menunjuk kepada peranan individu bukan hanya sebagai bidak bidak di dalam papan catur kebudayaan. Individu adalah kreator dan sekaligus manipulator kebudayaannya. Di dalam hal ini studi kebudayaan mengemukakan pengertian "sebab-akibat sirkuler" yang berarti bahwa antara kepribadian dan kebudayaan terdapat suatu interaksi yang saling menguntungkan. Di dalam perkembangan kepribadian diperlukan kebudayaan dan seterusnya kebudayaan akan dapat berkembang melalui kepribadian-kepribadian tersebut. Inilah yang disebut sebab-akibat sirkuler antara kepribadian dan kebudayaan.

Para pakar yang menaruh perhatian terhadap pendidikan dalam kebudayaan mula-mulanya muncul dari kaum behavioris dan psikoanalisis. Para ahli psikologi behaviorisme melihat perilaku manusia sebagai suatu reaksi dari rangsangan dari sekitarnya. Di sinilah peran pendidikan di dalam pembentukan perilaku manusia. Begitu pula psikolog aliran psikoanalis menganggap perilaku manusia ditentukan oleh dorongan-dorongan yang sadar maupun tidak sadar ini ditentukan antara lain oleh kebudayaan di mana pribadi itu hidup. John Gillin dalam Tilaar ${ }^{12}$ menyatukan pandangan

12 H.A.R. Tilaar, Education, Culture, and The Indonesian Civil Society: Indonesian Education Reform Policies for the Third Millennium, (Jakarta: Remaja Rosdakarya, 1999). 
behaviorisme dan psikoanalis mengenai perkembangan kepribadian manusia sebagai berikut: (1) Kebudayaan memberikan kondisi yang disadari dan yang tidak disadari untuk belajar. (2) Kebudayaan mendorong secara sadar ataupun tidak sadar akan reaksi-reaksi perilaku tertentu. Jadi selain kebudayaan meletakkan kondisi, yang terakhir ini kebudayaan merupakan perangsangperangsang untuk terbentuknya perilaku-perilaku tertentu. (3) Kebudayaan mempunyai sistem "reward and punishment" terhadap perilaku-perilaku tertentu. Setiap kebudayaan akan mendorong suatu bentuk perilaku yang sesuai dengan sistem nilai dalam kebudayaan tersebut dan sebaliknya memberikan hukuman terhadap perilaku-perilaku yang bertentangan atau mengusik ketenteraman hidup suatu masyarakat budaya tertentu. (4) Kebudayaan cenderung mengulang bentuk-bentuk kelakuan tertentu melalui proses belajar.

Pembahasan tentang "pendidikan agama" pada anak-anak Orang Kalang berinteraksi dengan kebudayaan Kalang. Di satu sisi, pendidikan agama mengintrodusir nilai-nilai mainstream, di sisi lain Orang Kalang berharap anak-anak mereka dapat meneruskan nilai-nilai budaya yang melekat turun temurun dalam kehidupan Orang Kalang.

\section{Pendidikan Agama di Lembaga Pendidikan Formal dalam Komunitas Kalang}

Para ahli pendidikan agama menyatakan bahwa pendidikan agama meliputi proses pembelajaran, pembiasaan, pembudayaan, pelatihan, penjernihan dan pencerahan nilai-nilai yang religius dalam mengembangkan fitrah kemanusiaan menuju kedewasaan. Sejalan dengan hal itu pula kegiatan pendidikan perlu mempertimbangkan potensi dan kultur lokal, karena produk yang diharapkan adalah generasi Muslim yang berakhlak mulia, mampu menjaga keseimbangan antara hubungan dengan Tuhan (hablun min Allāh), hubungan dengan manusia (hablun min al-nās) dan hubungan dengan alam (hablun min al-'âlam).13 Terkait dengan pandangan tersebut, menarik untuk dilihat bagaimana pendidikan agama berjalan di kalangan komunitas Kalang di Kendal.

13 Syamsuddin, "Tujuan Pendidikan Agama," makalah dalam Workshop Metodologi Pengajaran Agama SMP, 15-18 September 2005 di Banten.

Walisongo, Volume 19, Nomor 2, November 2011 
Sebagai salah satu bagian dari negara kesatuan Republik Indonesia, pendidikan agama di kalangan komunitas Kalang mengikuti sistem yang berlaku di kalangan berbagai komunitas lain di Indonesia. Jika untuk tujuan penyederhanaan dalam pemilahan sektor pendidikan tersebut, terdapat sektor formal, informal, dan nonformal, maka realitas yang ditemukan di kalangan komunitas Kalang adalah bahwa dalam sektor pendidikan formal maupun nonformal komunitas Kalang mengikuti pola yang berlaku dalam komunitas pada umumnya. Tidak ada spesifikasi atau kekhususan tertentu yang diterima oleh komunitas Kalang dalam perolehan pendidikan agama.

Pernyataan di atas dapat dijelaskan dari realitas yang ditemukan di Desa Sendang Dawuhan. Di Sendang Dawuhan terdapat dua buah Sekolah Dasar (SD) Negeri dan satu buah SMP Negeri. Sekolah Dasar Negeri telah berdiri di Sendang Dawuhan sejak tahun 1960-an, dan salah satu sekolah dasar, yaitu yang berada di dukuh Tempel merupakan sekolah induk. Sekolah induk adalah sekolah yang menjadi tempat pelaksana bagi ujian dari sekolahsekolah swasta yang ada di sekitar wilayah desa itu.

Sebagaimana sekolah-sekolah lain di wilayah negara ini, tata kelola sekolah, baik yang setingkat sekolah dasar maupun sekolah menengah mengacu pada ketentuan pendidikan agama yang berlaku. Oleh karena itu realitas yang ditemukan dalam komunitas Kalang menunjukkan bahwa generalisasi kurikulum dan model pembelajaran telah mendorong generalisasi fenomena pelaksanaan pendidikan agama di sekolah-sekolah. Kenyataan ini telah menimbulkan tidak tertampungnya nilai-nilai pemahaman lokal dalam pemahaman keagamaan.

Tidak tertampungnya nilai-nilai pemahaman lokal dalam pemahaman keagamaan selain disebabkan oleh dua hal, yaitu, kurikulum yang menggeneralisir realitas, juga model pemahaman guru terhadap pengajaran agama yang cenderung tidak memahami realitas setempat juga semakin membuat keragaman pemahaman keagamaan yang bersifat lokal semakin memudar. Pemahaman guru tentang pendidikan agama di jalur pendidikan formal yang seragam ini muncul karena beberapa sebab. Yang pertama, karena pengetahuan dasar dari guru agama di sekolah. Kedua, juga karena ketersediaan sumber referensi yang bersifat paket sehingga membuat nuansa pengajaran agama juga seragam. Ketiga, karena tidak adanya proses dialog antara sumber belajar di sekolah dengan sumber belajar di luar sekolah. 


\section{Pandangan terhadap Pendidikan Agama di Lembaga Pendidikan Formal dalam Komunitas Suku Kalang}

Proses pendidikan agama di kalangan komunitas Kalang ditanggapi oleh para informan secara beragam. Ada yang menyatakan bahwa pendidikan agama secara formal di sekolah sudah baik sehingga tidak perlu dipermasalahkan. Pandangan semacam ini muncul berdasarkan anggapan bahwa orang Kalang sama dengan orang Jawa pada umumnya. Oleh karena itu mereka memiliki hak dan kewajiban sebagai warga, yang sama sebagaimana warga masyarakat lainnya. Kalangan informan yang menyatakan tidak perlu mempersoalkan pendidikan agama di sekolah berpandangan bahwa pendidikan yang difasilitasi oleh pemerintah telah mencapai titik yang terbaik saat ini sehingga mereka harus mendukung program di sekolah tersebut.

Pandangan lain menyatakan bahwa orang Kalang tidak dapat berbuat apa-apa dengan adanya berbagai perkembangan. Pandangan semacam ini tampak di kalangan masyarakat Kalang yang memiliki kekhawatiran bahwa tradisi mereka akan luncur bersama proses berjalannya waktu. Kenyataan ini dapat dipahami karena dalam kenyataan semakin sedikit ekspresi Kalang tampak di dalam lingkup komunitas Kendal. Menurut mereka faktor pendidikan sangat menentukan kondisi tersebut.

\section{E. Pendidikan Agama dalam Kerangka Transmisi Nilai Agama}

Realitas keagamaan komunitas Kalang di Kendal menunjukkan kekhususan dibandingkan dengan komunitas Kalang yang ditemukan di berbagai wilayah lain di Jawa. Komunitas Kalang di Kendal ini menegaskan diri mereka sebagai orang Jawa, yang tidak berbeda dengan orang Jawa lainnya. Oleh karena itu mereka tidak mengupayakan apa pun untuk menegaskan ekspresi keagamaan komunitas Kalang. Mereka menyerahkan bentuk tradisi keagamaan generasi mudanya kepada generasi itu sendiri karena menurut mereka generasi itulah yang akan menghadapi realitas zaman.

\section{F. Kesimpulan}

Dari uraian di atas dapatlah diambil tiga kesimpulan. Pertama, komunitas Kalang mengintegrasikan diri sepenuhnya ke dalam lingkup komunitas pada umumnya dalam menjalani proses pendidikan agama di 
lembaga pendidikan formal. Sebagai lembaga formal, pendidikan agama di sekolah menggunakan pola dan standar baru menurut aturan sistem pendidikan nasional. Tidak ada akomodasi lokal yang diterapkan.

Kedua, ada beberapa pandangan dari komunitas Kalang mengenai pendidikan agama di lembaga pendidikan formal. Pandangan pertama menegaskan bahwa pendidikan formal telah berjalan baik sehingga perlu untuk didukung. Pandangan kedua menyatakan bahwa mereka tidak dapat berbuat apa-apa terhadap kenyataan pendidikan agama secara formal.

Ketiga, dalam kerangka transmisi nilai-nilai agama, Orang Kalang tampaknya tidak memberikan respon yang spesifik terhadap proses pendidikan agama di lembaga pendidikan formal. Hal ini karena mereka berpandangan bahwa Kalang tidak merujuk pada agama, namun pada tradisi, yaitu tradisi Kalang. Oleh karena itu terkait dengan transmisi nilai agama komunitas Kalang idak melakukan upaya apapun untuk mempertahankan identitas "ke-Kalang-an" mereka. [w] 


\section{BIBLIOGRAFI}

Abdullah, Prof. Dr. Irwan, Konstruksi dan Reproduksi Kebudayaan. Yogyakarta: Pustaka Pelajar, 2006.

Abuddin Nata, Peta Keragaman Pemikiran Islam Di Indonesia, Jakarta, Rajawali Pers, 2001.

Amin Abdullah, Islam Normatifitas dan Historisitas, Yogyakarta, Pustaka Pelajar, 1999.

Antlov, Hans dkk., Kepemimpinan Jawa, Perintah Halus Pemerintahan Otoriter, Yayasan Obor Indonesia, Jakarta, 2001.

Barth, Fredrik, Ethnic Groups and Boundaries: The Social Organization of Culture Difference, Bergen: Waveland Press, 1998.

Beatty, Andrew, "Adam and Eve and Vishnu: Syncretism in the Javanese Slametan" dalam The Journal of Anthropological institute 2 (Juni, 1996).

Bocock, Robert, Pengantar Komprehensif untuk Memahami Hegemoni, terj. Ikramullah Mahyuddin, Yogyakarta: Jalasutra, 2007.

Elizabeth, Misbah Zulfa, "Multi-etnisitas Indonesia dan Potensi Konflik di Dalamnya" dalam Mediasi dan Resolusi Konflik di Indonesia (Musahadi, ed.), Semarang: Walisongo Mediation Center, 2007.

Geertz, Clifford, Abangan, Santri, Priyayi dalam Masyarakat Jawa, Jakarta: Pustaka Jaya, 1981.

Hefner, Robert W., Hindu Javanese: Tengger Tradition an Islam, Princenton: Princeton University Press, 1985.

Ibnu Qoyim Isma'il, Religi Lokal dan Pandangan Hidup, Jakarta: Penerbit LIPI, Pusat Penelitian Kemasyarakatan dan Kebudayaan, Jakarta, 2004.

Joel, Kahn, Culture, Multiculture, Postculture, London: SAGE Publication, 1995.

Koentjaraningrat, Pokok-pokok Antropologi Sosial, Jakarta: Gramedia, 1999. , Pengantar Ilmu Antropologi, Jakarta: Rineka Cipta, 2002. Manusia dan Kebudayaan di Indonesia, Jakarta, Djambatan, 2002.

Kwak, Kyunghwa, "Adolescents and Their Parents: A Review of intergenerational Family Relations for Immigrant and Non-Immigrant Families" dalam Human Development, Kingstone: Queen's University, 2003. 
Lindholm, Charles, Culture and Identity: The History, Theory, and Practice of Psychological Anthropology, Oneworld Publications, 2007.

Muhadjir, Noeng, Metode Penelitian Kualitatif, Yogyakarta: Rake Sarasih, 1996.

Muhaimin AG, Islam dalam Bingkai Budaya Lokal Potret dari Cirebon, Jakarta: Logos, 2001.

Mujiran, Paulus, Republik Para Maling, Pustaka Pelajar, Jogjakarta, 1998.

Mulder, Niel, Agama, Hidup Sehari-Hari dan Perubahan Budaya, Jakarta: Gramedia Pustaka Utama, 1999.

Musahadi, dkk., Nalar Islam Nusantara, Jakarta: Diktis Depag RI, 2008.

Nakamura, Bulan Sabit di Atas Pohon Beringin/The Crescent Arises Over The Banyan Tree, Yogyakarta: Gadjah Mada University Press, 1974.

Nakamura, Mitsuo, Bulan Sabit Muncul dari Balik Pohon Beringin, Jogyakarta: UGM Press, 1983.

Nurcholish Madjid. Konsep dan Pengertian Akhlak Bangsa (Indonesia di Simpang Jalan), Jakarta: Mizan., 1998.

Nordholt, Nico Schule, Ojo Dumeh: Kepemimpinan Lokal dalam Paguyuban Pedesaan, Jakarta: Pustaka Sinar Harapan, 1987.

Pierre Bourdieu and Jean Claude Passeron, Reproduction in Education, Society and Culture, revised edition, New York: SAGE, 1990.

Rahman, Fazlur, Islam dan Modernitas, edisi terj., Bandung: Pustaka, 1994.

Raharjo, Slamet, Lagu Dolanan Jawa (Solmisasi). PGRI Krida karya. Semarang Sujamto, Otonomi, birokrasi, Partisipasi. Semarang: Dahara Prize, 2002.

Said, Edward, Orientalism, London: Routledge \& Kegan Paul, 1978.

Setiadi, Elly M, dkk. Ilmu Sosial dan Budaya Dasar, Jakarta: Kencana, 2006.

Sholeh, Ahmad, Upacara Obong, Tesis S2, PPS IAIN Walisongo 2004.

Stuart Hall, "Cultural Identity and Diaspora" dalam J. Rutherford (ed), Identity, Community, Culture, Difference, London: Lawrence and Wishart, 1990.

Suara Merdeka, 31 Januari 2008.

Sulardjo Pontjosutirto, “Antropologi Orang Kalang," hasil penelitian FH UGM, 1971.

Sutirman Eka Ardhana, Wong Kalang “Membangun Diri dengan Budaya Bisnis,"2003.

Syamsuddin, "Tujuan Pendidikan Agama," makalah dalam Workshop Metodologi Pengajaran Agama SMP, 15-18 September 2005 di Banten. 
Tilaar, H.A.R., Education, Culture, and The Indonesian Civil Society: Indonesian Education Reform Policies for the Third Millennium, Jakarta: Remaja Rosdakarya, 1999.

Kekuasaan dan Pendidikan, Suatu Tinjauan dari Perspektif Studi Kultural, Jakarta: Penerbit Indonesia Tera, 2003.

Tim Puspar UGM, Wawasan Budaya untuk Pembangunan; Menoleh Kearifan Lokal, Yogyakarta: Pilar Politika. 2004.

Yekti Maunati, Identitas Dayak: Komodifikasi dan Politik Kebudayaan, Jogyakarta: LKiS, 2006.

Woodward, Mark R., Islam in Jawa: Normative Piety and Mysticism in The Sultanate of Yogyakarta, An Arbor: UMI, 1989. 
